\title{
Corrigendum: The Paradoxical Role of Cellular Senescence in Cancer
}

\author{
Jing Yang ${ }^{1,2+}$, Mengmeng Liu ${ }^{1,2 t}$, Dongchun Hong ${ }^{1,2}$, Musheng Zeng ${ }^{2}$ and Xing Zhang ${ }^{1 *}$ \\ ${ }^{1}$ Melanoma and Sarcoma Medical Oncology Unit, State Key Laboratory of Oncology in South China, Collaborative Innovation \\ Center for Cancer Medicine, Sun Yat-sen University Cancer Center, Guangzhou, China, ${ }^{2}$ State Key Laboratory of Oncology in \\ South China, Collaborative Innovation Center for Cancer Medicine, Sun Yat-sen University Cancer Center, Guangzhou, China
}

Keywords: cancer, senescence, aging, senescence-associated secretory phenotype, senescent cell

\section{A Corrigendum on}

The Paradoxical Role of Cellular Senescence in Cancer by Yang, J., Liu, M., Hong, D., Zeng, M., and Zhang, X. (2021) Front. Cell Dev. Biol. 9:722205. doi: $10.3389 /$ fcell.2021.722205

In the original article in the first sentence of Introduction, Paragraph 1 there were incorrect citations of "Collado et al., 2007" and "Loaiza and Demaria, 2016". It should instead be "Hayflick and Moorhead, 1961" and "Hayflick, 1965". The correct paragraph appears as below.

"The cellular senescence was first described by Hayflick and colleagues in which they observed that after serial cultivation in vitro, normal human fibroblasts exhausted their capacity to divide and entered a state of irreversible growth arrest, whereas cancer cells did not enter this growth arrest state (Hayflick and Moorhead, 1961; Hayflick, 1965)."

The authors apologize for this error and state that this does not change the scientific conclusions of the article in any way. The original article has been updated.

\footnotetext{
tThese authors have contributed
} equally to this work and share first authorship

Specialty section:

This article was submitted to Molecular and Cellular Oncology,

a section of the journal

Frontiers in Cell and Developmental

Biology

Received: 17 August 2021 Accepted: 02 September 2021

Published: 23 September 2021

Citation:

Yang J, Liu M, Hong D, Zeng $M$ and Zhang X (2021) Corrigendum: The

Paradoxical Role of Cellular Senescence in Cancer. Front. Cell Dev. Biol. 9:759761. doi: 10.3389/fcell.2021.759761

\section{REFERENCES}

Collado, M., Blasco, M. A., and Serrano, M. (2007). Cellular senescence in cancer and aging. Cell 130, $223-233$. Hayflick, L., and Moorhead, P. S. (1961). The serial cultivation of human diploid cell strains. Exp. Cell Res. 25, 585-621.

Hayflick, L. (1965). The limited in vitro lifetime of human diploid cell strains. Exp. Cell Res. 37, 614-636. doi: 10.1016/0014-4827(65)90211-9

Loaiza, N., and Demaria, M. (2016). Cellular senescence and tumor promotion: Is aging the key? Biochim. Biophys. Acta. 1865 , 155-167. doi: 10.1016/j.bbcan.2016.01.007

Publisher's Note: All claims expressed in this article are solely those of the authors and do not necessarily represent those of their affiliated organizations, or those of the publisher, the editors and the reviewers. Any product that may be evaluated in this article, or claim that may be made by its manufacturer, is not guaranteed or endorsed by the publisher.

Copyright (C) 2021 Yang, Liu, Hong, Zeng and Zhang. This is an open-access article distributed under the terms of the Creative Commons Attribution License (CC BY). The use, distribution or reproduction in other forums is permitted, provided the original author(s) and the copyright owner(s) are credited and that the original publication in this journal is cited, in accordance with accepted academic practice. No use, distribution or reproduction is permitted which does not comply with these terms. 